\title{
Novedades de la Suprema Corte Bonaerense y de la Corte Suprema Naciónal.
}

Por Francisco Orsini y Juan Francisco Diaz

a) Jurisprudencia

Carácter abstracto de la cuestión relativa a la culpabilidad e inocencia en el divorcio en virtud de las cláusulas del Código Civil y Comercial

La Suprema Corte de Justicia resolvió, por mayoría, declarar abstracta la cuestión relativa a la culpabilidad e inocencia en el divorcio. Ordenó que la causa vuelva a la instancia de origen a los efectos de que las partes adecuen sus pretensiones a la nueva normativa vigente.

SCBA, "M. L. V. contra C. , F.O. Divorcio contradictorio", C. 120.109, 22 de febrero de 2017. Se debe escuchar al padre biológico en una causa por adopción plena

La Suprema Corte de Justicia resolvió, por mayoría, hacer lugar al recurso extraordinario deducido, disponiendo que los autos vuelvan a la instancia de origen a los fines de que se integre la litis con el padre biológico del menor, se proceda a analizar su pretensión y, posteriormente -en el menor plazo posible- se dicte el nuevo pronunciamiento respecto al menor, atendiendo fundamentalmente a su interés superior.

SCBA, “G. , C. M. y otro. Adopción. Acciones vinculadas”, C. 119.871, 19 de abril de 2017. Inaplicabilidad de la suspensión del juicio a prueba en casos de violencia contra la mujer

La Suprema Corte de Justicia resolvió hacer lugar al recurso extraordinario de inaplicabilidad de ley interpuesto por el Fiscal de Casación y dejó sin efecto el fallo que revocaba una decisión de la Sala Primera de la Cámara de Apelación y Garantías en lo Penal del Departamento Judicial Bahía Blanca que había confirmado el auto que disponía no hacer lugar a la concesión de la suspensión de juicio a prueba en un caso de violencia de género. El Máximo Tribunal ordenó remitir -con carácter urgente- las actuaciones al Tribunal de Casación para que dicte nuevo pronunciamiento a fin de evitar la posibilidad de incumplir con las obligaciones impuestas al Estado Argentino por el derecho internacional.

SCBA, "Altuve, Carlos Arturo. Recurso extraordinario de inaplicabilidad de ley en causa $n^{\circ}$ 74.617 del Tribunal de Casación Penal, Sala V”, P. 128.468, 12 de abril de 2017.

b) Cuestiones administrativas e institucionales

Actos procesales que pueden ser presentados con sola firma de abogados

El Máximo Tribunal de la Provincia de Buenos Aires, a través del Acuerdo 3842/17 firmado el 8 de marzo pasado, determinó qué actos procesales son considerados de mero trámite a los fines del artículo 56 inciso c) de la ley 5177, es decir, aquellos que en el nuevo Sistema de Presentaciones Electrónicas se presentan con la sola firma de los profesionales.

Nuevo reglamento para notificaciones electrónicas

A través del Acuerdo 3845/17 se estableció un nuevo reglamento de notificaciones elec- 
trónicas. La medida es de sumo interés para los letrados bonaerenses dado que el nuevo sistema se encuentra en plena aplicación en los litigios ante el Poder Judicial provincial. La Corte sostuvo que la Corte Interamericana de Derechos Humanos no puede revocar sentencias del Máximo Tribunal argentino

Así lo afirmó el Máximo Tribunal al desestimar una presentación de la Dirección de Derechos Humanos del Ministerio de Relaciones Exteriores y Culto por la cual se solicitaba que, como consecuencia del fallo de la Corte Interamericana dictado en la causa "Fontevecchia y otros c/ República Argentina", se dejara sin efecto una sentencia firme de la Corte Suprema. La mayoría fue integrada en voto conjunto de Lorenzetti, Highton de Nolasco y Rosenkrantz y el voto propio del juez Rosatti. En disidencia votó el juez Maqueda por la obligatoriedad plena para la corte nacional de las decisiones de la Interamericana.

CSJN, "Ministerio de Relaciones Exteriores y Culto s/ Informe sentencia dictada en el caso 'Fontevecchia y D'Amico", 14 de febrero de 2017.

\section{Validez de la cláusula constitucional que limita la función judicial a los 75 años}

El Máximo Tribunal resolvió la causa "Schiffrin" donde se discutió la validez de una cláusula de la Constitución Nacional incorporada por la Convención Reformadora de 1994. La Corte, por mayoría integrada por Lorenzetti, Maqueda y Rosatti, modificó su precedente "Fayt" y consideró que la Convención Constituyente de 1994 se encontraba facultad para establecer el límite constitucional de 75 años de edad para la función judicial. El juez Rosenkrantz, en disidencia, reparó en la necesidad de ajustarse a los precedentes. El nuevo criterio afecta a unos 70 jueces federales en funciones que se deberán, ahora, retirar u obtener una nueva designación.

CSJN, "Schiffrin, Leopoldo Héctor c/ Poder Ejecutivo Nacional s/ acción meramente declarativa", 28 de marzo de 2017.

El personal de la Policía de la provincia de Buenos Aires no tiene derecho a sindicalizarse

Así lo dispuso, por mayoría, el Máximo Tribunal al sostener que el personal de las fuerzas de la policía no tiene un derecho colectivo a sindicalizarse. Los jueces Lorenzetti, Highton y Rosenkrantz votaron en ese sentido; Maqueda y Rosatti en disidencia. La Procuradora General Gils Carbó, había recomendado rechazar el recurso de queja "ante la ausencia de una ley expresa”.

CSJN, "Recurso de hecho deducido por el actor en la causa Sindicato Policial Buenos Aires c/ Ministerio de Trabajo s/ ley de asociaciones sindicales'”, 11 de abril de 2017.

\section{Aplicación del cómputo $2 \times 1$ a la prisión en casos de lesa humanidad}

El Máximo Tribunal resolvió, por mayoría integrada por los ministros Highton, Rosenkrantz y Rosatti, declarar aplicable la ley 24.390 (conocida como 2x1), que estuvo vigente entre los años 1994 y 2001, hoy derogada, que reduce el cómputo de la prisión, porque se trata de la ley más benigna. En disidencia, votaron los jueces Lorenzetti y Maqueda, quienes señalan que esa reducción no es aplicable a los delitos de lesa humanidad. CSJN, "Recurso de hecho deducido por la defensa de Luis Muiña en la causa Bignone, Reynaldo Benito Antonio y otro s/ recurso extraordinario", 3 de mayo de 2017. 